\title{
Verbenaceae na Serra Negra, Minas Gerais, Brasil
}

\author{
Verbenaceae in the Serra Negra, Minas Gerais, Brazil
}

\author{
Pedro Henrique Cardoso ${ }^{1}$, Andressa Cabral ${ }^{1}$, Vanessa Imaculada dos Reis Valério ${ }^{1}$ \\ \& Fátima Regina Gonçalves Salimena ${ }^{1,2}$
}

\begin{abstract}
Resumo
Apresenta-se um estudo taxonômico da família Verbenaceae na Serra Negra, região incluída no Complexo da Mantiqueira, situada ao sul da Zona da Mata de Minas Gerais, Brasil. São encontrados quatro gêneros e cinco espécies: Lantana camara, L. fucata, Lippia origanoides, Stachytarpheta mexiae e Verbena rigida. É apresentado o primeiro registro de S. mexiae para o Domínio Atlântico. São incluídos chave de identificação, descrições, ilustrações, comentários taxonômicos, ecológicos e de distribuição geográfica para as espécies. Palavras-chave: Complexo da Mantiqueira, Floresta Atlântica, florística, taxonomia.
\end{abstract}

\begin{abstract}
A taxonomic study of the Verbenaceae in the Serra Negra, included in the Mantiqueira Complex, located in the south of the Zona da Mata of Minas Gerais, Brazil, is presented. Four genera and five species were found: Lantana camara, L. fucata, Lippia origanoides, Stachytarpheta mexiae and Verbena rigida. The first record of the $S$. mexiae for the Atlantic Domain is presented. Identification keys, descriptions, illustrations, taxonomic comments, ecological and of geographic distribuition for the species are included.
\end{abstract}

Key words: Mantiqueira Range, Atlantic Forest, floristic, taxonomy.

\section{Introdução}

Verbenaceae reúne 34 gêneros e cerca de 1.200 espécies amplamente distribuídas na Região Neotropical, com poucos representantes na Europa, Ásia, África e Madagascar (Atkins 2004). O Brasil constitui um importante centro de diversidade da família, onde são conhecidos 16 gêneros e 276 espécies, com 174 endêmicas (BFG 2015), 50 consideradas raras (Salimena et al. 2009), e 27 estão ameaçadas de extinção (Salimena et al. 2013a; Salimena et al. 2014), com maior riqueza nos cerrados e campos rupestres.

As espécies de Verbenaceae têm seu potencial econômico amplamente explorado, tanto como ornamentais, quanto terapêuticas, devido aos diferentes usos dos óleos essenciais, sendo de grande importância na medicina popular, na preparação de alimentos e no fornecimento de substratos para as indústrias de fármacos e de cosméticos (Lorenzi \& Souza 2001; Pascual et al. 2001; Stashenko et al. 2003).
No Brasil foram realizados importantes estudos referentes à família, como o tratamento clássico de Schauer para a flora brasileira (1847), além das contribuições de algumas floras estaduais e regionais (Harley \& Simmons 1986; Atkins 1995; Luizi-Ponzo 1997; Salimena-Pires \& Giulietti 1998; Salimena 2000; Salimena \& Silva 2009; Santos et al. 2009; Salimena et al. 2016).

A Floresta Atlântica está entre as mais importantes e megadiversas fitofisionomias tropicais do mundo, sendo considerada prioridade em termos de conservação devido à grande fragmentação a que foi submetida. Nos últimos 500 anos, este domínio fitogeográfico perdeu mais de $92 \%$ de sua área, e restam hoje cerca de $100.000 \mathrm{~km}^{2}$ de vegetação original, a maioria em fragmentos concentrados em áreas de relevo acidentado das regiões Sul e Sudeste do país (Hirota 2005). A preocupação com a conservação deste domínio acarreta uma demanda urgente de seu conhecimento. Nesta perspectiva, levantamentos

\footnotetext{
${ }^{1}$ Universidade Federal de Juiz de Fora, Inst. Ciências Biológicas, Depto. Botânica, Campus Universitário s/n, São Pedro, 36036-900, Juiz de Fora, MG, Brasil.

${ }^{2}$ Autor para correspondência: frsalimena@gmail.com
} 
florísticos têm sido amplamente reconhecidos como ferramentas primordiais para documentar a diversidade de plantas de uma região (Clarke \& Funk 2005; GSPC 2006).

A Serra da Mantiqueira abriga $20 \%$ dos remanescentes da Floresta Atlântica mineira (Costa \& Herrmann 2006). Considerada de alta riqueza de espécies de fauna e flora raras, endêmicas e ameaçadas, é reconhecida como área prioritária para a conservação da biodiversidade em Minas Gerais (Drummond et al. 2005).

A Serra Negra integra o corredor ecológico do Complexo da Mantiqueira e sua flora vem sendo objeto de estudos sistemáticos desde 2003 conduzidos pela Universidade Federal de Juiz de Fora (Salimena et al. 2013b), indicando que representa uma área notavelmente diversa (Menini Neto et al. 2009). No entanto, a região sofre com intensa pressão antrópica em decorrência da agropecuária, do reflorestamento de Pinus L. e Eucalyptus L'Her., da especulação imobiliária (Drummond et al. 2005), além do turismo desordenado, da coleta ilegal de plantas e utilização de suas áreas campestres como pastagens, levando muitos táxons ao risco de extinção (Gonzaga et al. 2014). Com a publicação dos primeiros resultados de sua flora, esforços recentes têm sido desenvolvidos pelo Instituto Estadual de Florestas de Minas Gerais, para a criação de uma Unidade de Conservação para proteção desta área, que conta com poucas RPPNs.

Vários estudos foram realizados na região da Serra Negra com o objetivo de ampliar o conhecimento de sua diversidade vegetal (Menini Neto et al. 2009; Abreu et al. 2011; Feliciano \& Salimena 2011; Matozinhos \& Konno 2011; Valente et al. 2011; Blaser et al. 2012; Dutra et al. 2012; Souza et al. 2012; Mezzonato-Pires et al. 2013; Salimena et al. 2013b; Gonzaga et al. 2014; Cabral et al. 2016; Justino et al. 2016). Dando continuidade aos estudos florísticos na Serra Negra, o presente trabalho apresenta um estudo taxonômico das espécies de Verbenaceae, incluindo descrições, ilustrações, chaves de identificação, comentários de distribuição geográfica, ecológicos e taxonômicos, contribuindo com a ampliação do conhecimento florístico na região e no estado de Minas Gerais.

\section{Material e Métodos}

A Serra Negra localiza-se no sul da Zona da Mata mineira, estando inserida no Complexo da Mantiqueira. A região abrange parte dos municípios de Lima Duarte, Santa Bárbara do Monte Verde, Rio Preto e Olaria $\left(22^{\circ} 05^{\prime} \mathrm{S}\right.$ e $\left.43^{\circ} 49^{\prime} \mathrm{W}\right)$, com uma área aproximada de 10.000 ha. A vegetação está inserida no Domínio Atlântico, apresentando um mosaico composto por campos rupestres e remanescentes de Floresta Ombrófila Densa Aluvial, Floresta Ombrófila Densa Montana, Floresta Ombrófila Alto Montana e fragmentos da Floresta Estacional Semidecidual, além de áreas arbustivas e antrópicas. A região apresenta altitudes variando entre 800 e 1.700 m.s.m. O clima é do tipo Cwb (Köppen), mesotérmico úmido, com invernos secos e frios e verões brandos e úmidos, apresentando uma precipitação média anual de 1886mm (Menini Neto et al. 2009; Valente et al. 2011; Salimena et al. 2013b). O inventário florístico foi realizado através de expedições entre os anos de 2003 e 2010 vinculadas ao projeto "Estudos Florísticos na Serra Negra, Minas Gerais" desenvolvido pela Universidade Federal de Juiz de Fora, complementado por coletas específicas durante os anos de 2013 e 2014. Os espécimes férteis foram coletados, tendo suas principais características anotadas em campo, herborizados segundo metodologia de Fidalgo \& Bononi (1984) e depositadas no Herbário Leopoldo Krieger - CESJ (acrônimo segundo Thiers, continuamente atualizado). As descrições morfológicas das espécies seguiram a terminologia proposta por Radford (1974), Harris \& Harris (2003) e Gonçalves \& Lorenzi (2007). O material examinado está listado em ordem alfabética de município e localidades específicas, sendo adotada a ordem cronológica no caso de haver mais de um material nestas condições.

\section{Resultados e Discussão}

A família Verbenaceae está representada na Serra Negra por cinco espécies distribuídas em quatro gêneros: Lantana camara L., L. fucata Lindl., Lippia origanoides Kunth, Stachytarpheta mexiae Mold. e Verbena rigida Spreng.

A riqueza da família Verbenaceae na Serra Negra é inferior à encontrada para outras regiões do estado de Minas Gerais como Grão Mogol (Salimena \& Silva 2009) e Serra do Cipó (Salimena-Pires \& Giulietti 1998) ambas com registros de 13 espécies, o que confirma a maior representatividade desta família no cerrado (Salimena et al. 2013a)

A única espécie considerada ruderal e invasora (Moro et al. 2012) é Lantana camara com ampla distribuição, enquanto L. fucata também 
com distribuição na América tropical e subtropical é reconhecida como espécie ruderal (Silva 1999; Silva \& Lima 2012). Lippia origanoides ocorre desde o sul dos Estados Unidos até a Argentina e no Brasil (O’Leary et al. 2012), nos cerrados e campos rupestres, com poucos registros para a Floresta Atlântica, sendo que na região da Serra da Mantiqueira, até este trabalho só apresentava registros de ocorrência no Parque Estadual do Ibitipoca (Forzza et al. 2013). Verbena rigida tem distribuição na América do Sul (O'Leary et al. 2007), e no Brasil é encontrada nas regiões Sul e Sudeste, nos campos de altitude, campos rupestres, associada à Floresta Ombrófila Mista e áreas antropizadas (O’Leary 2018). A espécie com distribuição mais restrita é $S$. mexiae que só apresentava registros de ocorrência para a Cadeia do Espinhaço em Minas Gerais (Salimena-Pires \& Giulietti 1998; Atkins 2005), sendo este o primeiro registro da espécie para o Domínio Atlântico.

A ocorrência de L. origanoides e $S$. mexiae na Serra Negra confirma a disjunção florística de algumas regiões do sul de Minas Gerais, incluindo a Serra do Ibitipoca, com a Cadeia do Espinhaço, já relatada por Giulietti \& Pirani (1988). Dessa maneira a Serra Negra representa uma área de transição entre os campos rupestres da Cadeia do Espinhaço e os campos de altitude da Serra da Mantiqueira, conforme apresentado por Forzza et al. (2013), com base na distribuição de vários táxons compartilhados entre a Serra do Ibitipoca e demais áreas da Região Sudeste do Brasil.

\section{Tratamento taxonômico}

Verbenaceae J. St.-Hil.

Ervas, arbustos, subarbustos, árvores ou lianas, dióicas ou monóicas, geralmente aromáticas. Folhas opostas, verticiladas, raro alternas, simples, margem inteira, serreada ou crenada, sésseis, subsésseis ou pecioladas, sem estípulas. Inflorescências axilares ou terminais, racemosas; brácteas foliáceas ou membranáceas, verdes ou róseas; cálice gamossépalo, tetrâmero ou pentâmero, tubuloso, campanulado ou cilíndrico; corola gamopétala, tetrâmera ou pentâmera, actinomorfa ou zigomorfa, tubulosa, infundibuliforme ou hipocrateriforme, tubo estreito, limbo 5-lobado, raro 4-8-lobado; estames 4 , alternos com os lobos da corola, geralmente didínamos ou 2 perfeitos e 2 estaminódios, filetes livres, anteras bitecas, tecas paralelas ou divergentes, deiscência longitudinal; gineceu 2-4 carpelar, um dos carpelos geralmente abortivo; ovário súpero, óvulos 1 por lóculo, anátropos; estilete terminal, estigma capitado, terminal ou oblíquo, lateral, decurrente. Fruto drupa ou esquizocarpo, sementes sem endosperma, embrião reto, cotilédones geralmente crassos e lisos.

\section{Chave de identificação das espécies de Verbenaceae da Serra Negra}

1. Inflorescências 2,5-5 cm compr., espigas cilíndricas; estames 2 perfeitos, 2 estaminódios, tecas divergentes. 3.1. Stachytarpheta mexiae

1'. Inflorescências 0,4-3 cm compr., espigas tetragonais ou corimbosas; estames 4 perfeitos, didínamos, tecas paralelas.

2. Fruto drupa.

3. Ramos aculeados, inflorescências 2 por axila, brácteas iguais, ca. $3 \mathrm{~mm}$ compr., oblongolanceoladas, corola vermelha e amarela. 1.1. Lantana camara

3'. Ramos inermes, inflorescência 1 por axila, brácteas desiguais, externas ca. 6 mm compr., largo-ovais, internas ca. $3 \mathrm{~mm}$ compr., ovais, corola rósea ou lilacínea.... 1.2. Lantana fucata

2'. Fruto esquizocarpo.

4. Folhas sésseis, corola roxa, esquizocarpo separando em 4 mericarpos na maturidade 4.1. Verbena rigida

4'. Folhas pecioladas, corola alva, esquizocarpo separando em dois mericarpos na maturidade... 2.1. Lippia origanoides

\section{Lantana L.}

Arbustos, monóicos, ramos inermes ou aculeados, tetragonais, hirsuto-glandulosos. Folhas opostas, lâmina cartácea, discolor, tricomas glandulares presentes, pecioladas.
Inflorescências corimbosas, espigas axilares, 1-2 por axila, bracteosas; brácteas iguais ou desiguais, imbricadas, dispostas espiraladamente, ovais, largo-ovais ou oblongo-lanceoladas, foliáceas, verdes, externamente seríceas ou tomentosas; cálice 
4-5 laciniado, membranáceo, verde, externamente seríceo ou tomentoso, tubuloso; corola zigomorfa, hipocrateriforme, tubo cilíndrico, 5-lobada, lobos desiguais, branca, vermelha, amarela, rosa ou lilás, externamente pubescente; estames 4, perfeitos, didínamos, inseridos na metade do tubo da corola, tecas paralelas; ovário ovoide ou globoso, 2-locular, lóculos 1-seminado, estigma oblíquo. Fruto drupa, esférico ou ovoide, verde, vináceo ou negro, superfície externa rugosa, mesocarpo suculento, 1-pirenado.

Lantana reúne aproximadamente 150 espécies distribuídas nas Américas desde a Argentina até o sul dos Estados Unidos, com alguns representantes na África e Ásia. O centro de diversidade do gênero compreende o Brasil, norte da Argentina e parte da Bolívia (Atkins 2004; Silva 1999). No Brasil ocorrem 20 espécies, com 10 endêmicas (BFG 2015).

\subsection{Lantana camara L., Sp. pl. 2:627. 1753.}

Fig. 1a

Arbustos ca. $0,5 \mathrm{~m}$ alt., ramos tetragonais, aculeados. Folhas 3-6 × 1,5-4 cm, lâmina oval a elíptica, face adaxial hirsuta, nervuras impressas, face abaxial hirsuta, nervuras proeminentes, ápice agudo-acuminado, margem crenada, ciliada, base atenuada, pecíolo 6-11 mm compr., hirsutoglanduloso. Inflorescências hemisféricas, ca. $1 \mathrm{~cm}$ compr., 2 por axila, pedúnculo $17-35 \mathrm{~mm}$ compr., hirsuto-glanduloso, raque hirsuta; brácteas iguais, ca. $3 \mathrm{~mm}$ compr., oblongo-lanceoladas, externamente tomentosas, ápice agudo, margem ciliada, base truncada; cálice ca. $3 \mathrm{~mm}$ compr., 4-laciniado, tomentoso; corola ca. $10 \mathrm{~mm}$ compr., vermelha e amarela, fauce amarela; ovário ovoide. Fruto ca. $4 \times 3 \mathrm{~mm}$, ovoide, imaturo verde, maduro negro.

Material examinado: Rio Preto, Funil, Fazenda Tiririca, Serra da Caveira D'Anta, 24.IV.2004, fl. e fr., K. Antunes et al. 103 (CESJ).

Lantana camara pode ser reconhecida pelos ramos tetragonais aculeados, inflorescências hemisféricas, brácteas iguais, caducas na frutificação, corola vermelha e amarela. É uma espécie nativa da América tropical e subtropical, porém atualmente ocorre em diferentes partes do mundo, onde tornou-se ruderal, invasora de culturas, além de cultivada para fins ornamentais (Lorenzi 1991; Silva 1999). No Brasil é a espécie de Lantana com distribuição mais ampla, encontrada em todos os domínios fitogeográficos como planta ruderal (BFG 2015). Na Serra Negra ocorre em ambientes antropizados incluindo beira de estradas, trilhas e borda de floresta, sendo rara acima de $1.200 \mathrm{~m}$ de altitude. Foi coletada com flores e frutos em abril.

1.2. Lantana fucata Lindl. Bot. Reg., 10: t. 798, 1824.

Fig. 1b

Arbustos 1,5-2 m alt., ramos inermes, eretos. Folhas $0,7-6,5 \times 0,5-3 \mathrm{~cm}$, lâmina oval a elíptica, face adaxial hirtela, nervuras impressas, face abaxial hirtela, mais densamente nas nervuras, nervuras proeminentes, ápice agudo a obtuso, margem serreada, ciliada, base atenuada, pecíolo $2-5 \mathrm{~mm}$ compr., tomentoso. Inflorescências $(0,4-) 1-1,5 \mathrm{~cm}$ compr., 1 por axila, pedúnculos $22-35 \mathrm{~mm}$ compr., hirsuto-glandulosos, raque tomentosa-glandulosa; brácteas desiguais, externas ca. $6 \mathrm{~mm}$ compr., largo-ovais, internas ca. $3 \mathrm{~mm}$ compr., ovais, externamente seríceas, ápice agudo-acuminado, margem ciliada, base truncada; cálice ca. $2 \mathrm{~mm}$ compr., 4-5-laciniado, seríceo; corola ca. $10 \mathrm{~mm}$ compr., lilás ou rosa, fauce amarela a alva; ovário globoso. Fruto ca. 2,5 $\times 4 \mathrm{~mm}$, largo-ovoide, negro. Material examinado: Lima Duarte, RPPN Serra Negra: 11.V.2008, fl., N.L. Abreu \& L. Menini Neto 228 (CESJ). Olaria, Serrinha, Sítio do Rinaldo Degredo, 22.VIII.2009, f1., J.H.C. Ribeiro et al. 201 (CESJ).Rio Preto, Funil, Fazenda Tiririca, Serra da Caveira D'Anta, 24.IV.2004, fl., K. Antunes et al. 101 (CESJ); RPPN São Lourenço do Funil, 8.XII.2007, fl. e fr., F.S. Souza et al. 295 (CESJ); trilha para Antena, 23.IV.2013, fl., K. Antunes \& R.J.V. Alves 445 (CESJ); trilha para a cachoeira do Marciano, 13.VII.2008, fl., N.L. Abreu et al. 261 (CESJ); trilha para a cachoeira do Ninho de Égua, 19.XI.2005, fl. e fr., N.L. Abreu et al. 31 (CESJ). Vila do Funil, propriedade do sr. Nenê Roque, subida para Antena, 22.XI.2014, f1., F.R.G. Salimena et al. 3799 (CESJ).

Lantana fucata se caracteriza pelas folhas com face adaxial e abaxial hirtelas além de brácteas desiguais, persistentes na frutificação. Está amplamente distribuída na América tropical e subtropical. No Brasil ocorre nas regiões Nordeste, Centro-Oeste, Sudeste e Sul (BFG 2015). Na Serra Negra é encontrada em campo rupestre, em borda de trilha. Foi coletada com flores em abril, maio, julho, agosto, novembro e dezembro, e com frutos em novembro e dezembro.

\section{Lippia L.}

2.1. Lippia origanoides Kunth, Nov. Gen. Sp. 2: 267. 1817 [1818].

Fig. 1c-j

Arbustos ou subarbustos, monóicos, $0,4-2 \mathrm{~m}$ alt., aromáticos, ramos inermes, eretos, cilíndricos, hirsutos. Folhas 0,9-4,5 × 0,4-2,4 cm, opostas, lâmina oval, oval-elíptica ou oblonga, cartácea, 

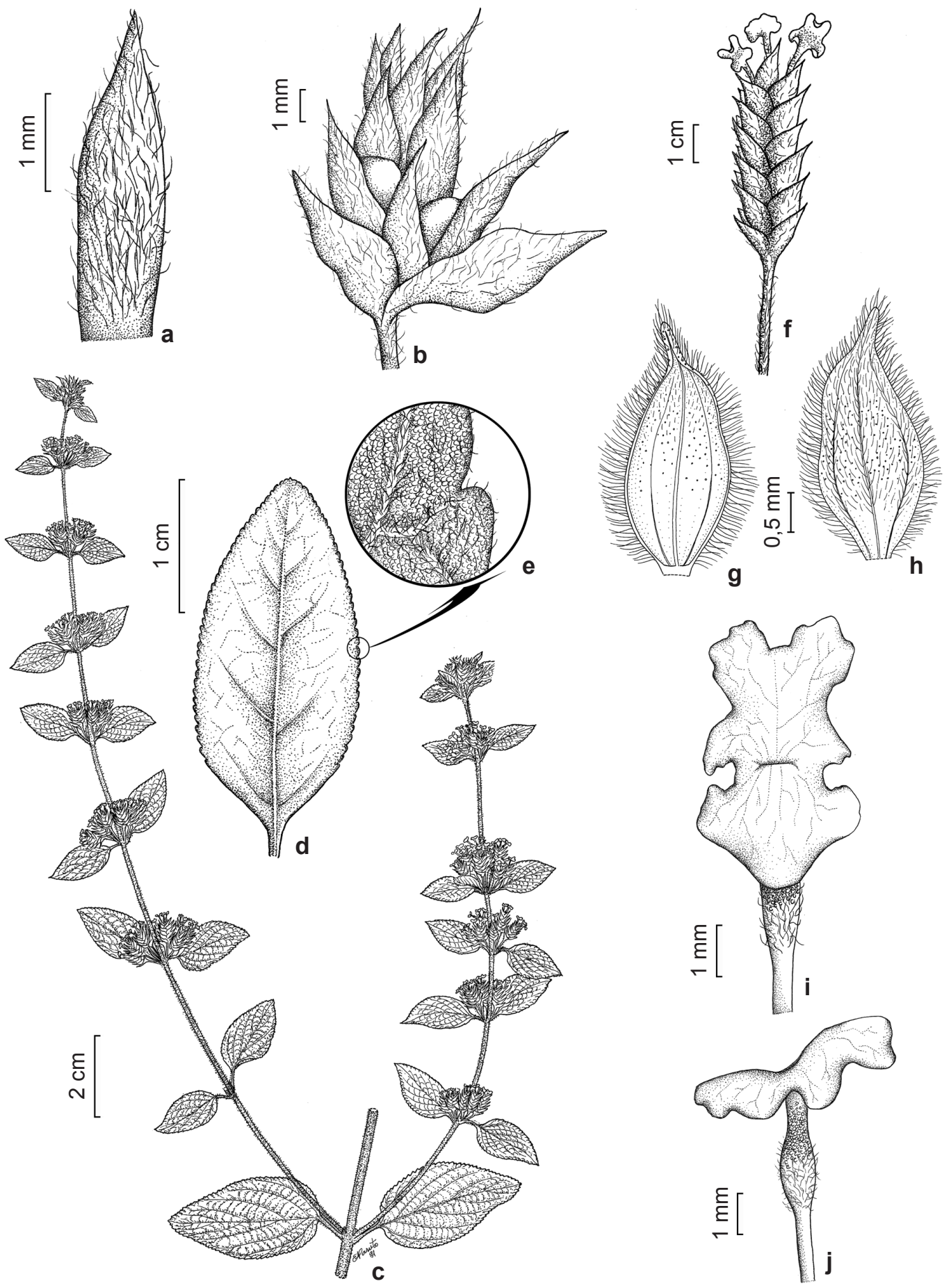

Figura 1 - a. Lantana camara - face externa da bráctea. b. Lantana fucata - infrutescência. c-j. Lippia origanoides - c. hábito; d. face abaxial da folha; e. detalhe do indumento e margem da folha; f. inflorescência; g. face interna da bráctea; h. face externa da bráctea; i. vista frontal da flor; j. vista lateral da flor (a. Antunes et al. 103; b. Souza et al. 295; c-j. Salimena et al. 2660).

Figure 1 - a. Lantana camara - external side of the bract. b. Lantana fucata - infructescence. c-j. Lippia origanoides - c. habit; d. abaxial side of the leaf; e. detail of indument and margin of the leaf; f. inflorescence; g. internal side of the bract; h. external side of the bract; i. front view of the flower; j. lateral view of the flower (a. Antunes et al. 103; b. Souza et al. 295; c-j. Salimena et al. 2660). 
discolor, face adaxial serícea, nervuras impressas, face abaxial tomentosa, nervuras proeminentes, tricomas glandulares abundantes em ambas as faces, ápice agudo a obtuso, margem crenada, ciliada, base cuneada ou obtusa, pecíolo 3-10 $\mathrm{mm}$ compr., hirsuto-glanduloso. Inflorescências 0,4-1,5 cm compr., espigas axilares, tetragonais, 2-4 por axila, bracteosas, pedúnculos 4-10 $\mathrm{mm}$ compr., seríceo-glanduloso, raque hirsutoglandulosa; brácteas 2-4 mm compr., imbricadas, dispostas em 4 fileiras, lanceoladas, foliáceas, verdes, externamente hirsuto-glandulosas, ápice atenuado, margem ciliada, base truncada; cálice ca. $2 \mathrm{~mm}$ compr., 4-laciniado, membranáceo, verde, externamente hirsuto-glanduloso, tubuloso, acrescente no fruto; corola $3-5 \mathrm{~mm}$ compr., zigomorfa, hipocrateriforme, tubo cilíndrico, 4-lobada, lobos desiguais, alva, fauce amarela, externamente hirsuto-glandulosa; estames 4 perfeitos, didínamos, inseridos na metade do tubo da corola, tecas paralelas; ovário ovoide, 2 locular, lóculos 1-seminado, estigma oblíquo. Fruto esquizocarpo, ca. $2 \mathrm{~mm}$ compr., ovoide, castanho, superfície externa lisa, separando-se em 2 mericarpos na maturidade.

Material examinado: Lima Duarte, RPPN Serra Negra, Cachoeira da Borboleta Azul, 1.III.2008, fl., F.R.G. Salimena et al. 2660 (CESJ); 5.IV.2009, fl., J.H.C. Ribeiro et al. 86 (CESJ); 20.IV.2009, fl. e fr., $L$. Menini Neto et al. 679 (CESJ). Olaria, Serrinha, Sítio do Rinaldo Degredo, 28.VII.2009, fl. e fr., F.S. Souza et al. 751 (CESJ).

Lippia reúne cerca de 200 táxons com ampla distribuição na Região Neotropical, nas regiões áridas do sudoeste dos Estados Unidos, florestas tropicais decíduas da América Central e nos campos rupestres e cerrados do Brasil, regiões de altos índices de endemismos. Na África sua ocorrência também coincide com centros de alto endemismo, na região leste, associada às montanhas mais altas (Atkins 2004). No Brasil, ocorrem 83 espécies, das quais 59 são endêmicas (BFG 2015).

Lippia origanoides se carateriza por apresentar inflorescências tetrásticas, diminutas, com 4 séries de brácteas e flores alvas com alto polimorfismo foliar (O'Leary et al. 2012). É a espécie mais amplamente distribuída do gênero, ocorrendo nas Américas na Bolívia, Brasil, Guiana, Paraguai, norte da Argentina, Costa Rica, México e Venezuela e sul dos Estados Unidos (O'Leary et al. 2012). No Brasil é encontrada nos domínios fitogeográficos da Amazônia, Caatinga, Cerrado e Floresta Atlântica (BFG 2015). Na Serra Negra é encontrada nos campos rupestres próximo a afloramentos quartzíticos em solo arenoso acima de $1.200 \mathrm{~m}$ de altitude. Foi coletada com flores nos meses de março, abril e julho, e com frutos nos meses de abril e julho.

\section{Stachytarpheta Vahl.}

3.1. Stachytarpheta mexiae Mold. Phytologia 1: 472-473. 1940.

Fig. 2a-g

Arbustos, monóicos, 1-1,8 m alt., ramos inermes, eretos, cilíndricos, hirsutos. Folhas 1-4 × 1,2-2,5 cm, opostas, lâmina oval a ovalelíptica, cartácea, discolor, face adaxial velutina, nervuras impressas, face abaxial densamente tomentosa, nervuras proeminentes, tricomas glandulares ausentes, ápice agudo, margem serreada a levemente crenada da metade até o ápice, ciliada, base atenuada, pecíolo 1-5 mm compr., hirsuto. Inflorescências 2,5-5 cm compr., espigas cilíndricas, terminais, bracteosas, pedúnculos inconspícuos, raque hirsuta; brácteas ca. $10 \mathrm{~mm}$ compr., imbricadas, apressas, estreito-lanceoladas, foliáceas, verdes, densamente hirsutas, ápice agudo, margem ciliada, base truncada; cálice ca. 10mm compr., 4-5-laciniado, membranáceo, verde, externamente hirsuto, cilíndrico-tubuloso, persistente no fruto; corola ca. $15 \mathrm{~mm}$ compr., zigomorfa, infundibuliforme a hipocrateriforme, tubo cilíndrico, externamente glanduloso, 4-lobada, lobos iguais, azul, fauce alva, glandulosa; estames 2 perfeitos, estaminódios 2, inseridos no terço superior do tubo da corola, tecas divergentes, ovário elíptico, 2-locular, lóculos 1-seminado, estigma capitado. Fruto esquizocarpo, ca. $5 \mathrm{~mm}$ compr., oblongo-elíptico, castanho, superfície externa papilhosa, separando-se na maturidade em 2 mericarpos.

Material examinado: Olaria, Serrinha, Sítio do Rinaldo Degredo, 22.VIII.2009, fl. e fr., J.A. Oliveira et al. 98 (CESJ). Rio Preto, RPPN São Lourenço do Funil, trilha para a RPPN da Serrinha, 19.VII.2013, fl. e fr., F.R.G. Salimena et al. 3586 (CESJ).

Stachytarpheta possui aproximadamente 133 espécies amplamente distribuídas na América tropical e subtropical e apenas uma espécie na África (Atkins 2005). No Brasil ocorrem 79 espécies, sendo 72 endêmicas, com maior riqueza nos campos rupestres de Minas Gerais, Goiás e da Bahia (BFG 2015).

Stachytarpheta mexiae se caracteriza por apresentar ramos hirsutos, folhas ovais, "velutinas" na face adaxial, inflorescências cilíndricas de 2-5 cm compr. e flores azuis. É endêmica de 

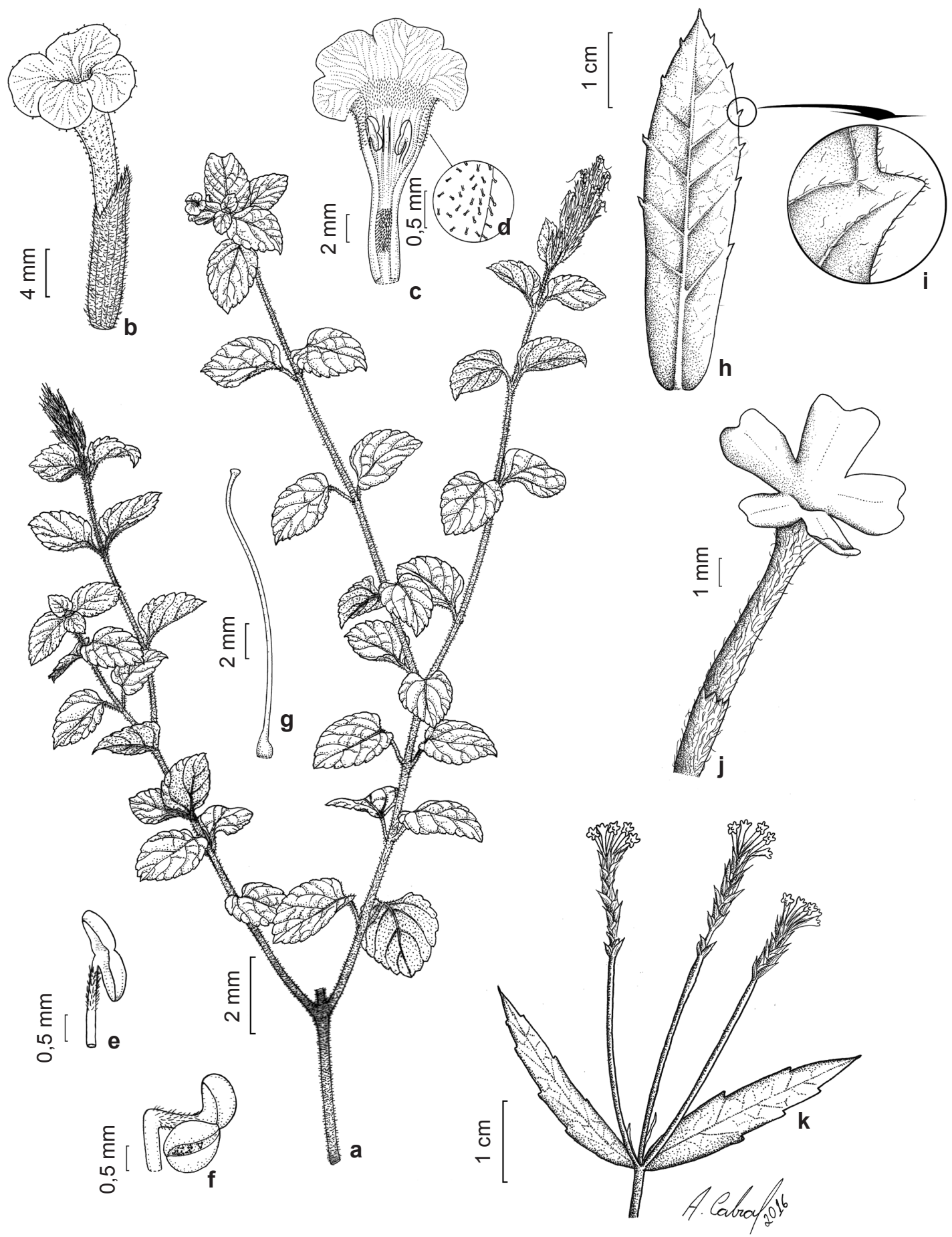

Figura 2 - a-g. Stachytarpheta mexiae - a. hábito; b. vista externa da flor; c. corte longitudinal da corola; d. detalhe do indumento externo do tubo da corola; e-f. detalhes dos estames perfeitos; g. gineceu. h-k. Verbena rigida - h. face abaxial da folha; i. detalhe do indumento da folha; j. vista externa da flor; k. hábito (a-g. Salimena et al. 3586; h-k. Salimena et al. 2616).

Figure 2 - a-g. Stachytarpheta mexiae - a. habit; b. external view of the flower; c. longitudinal section of the corolla; d. detail of external indument of corolla tube; e-f. details of perfect stamens; g. gynoecium. h-k. Verbena rigida - h. abaxial side of the leaf; i. detail of indument of the leaf; j. external view of the flower; k. habit (a-g. Salimena et al. 3586; h-k. Salimena et al. 2616). 
Minas Gerais, com registros anteriores apenas para os campos rupestres da Cadeia do Espinhaço (Salimena-Pires \& Giulietti 1998; Atkins 2005; BFG 2015) distribuição que foi ampliada neste trabalho para o Domínio Atlântico. Na Serra Negra, é encontrada em altitudes acima de $1.200 \mathrm{~m}$ em área restrita de campo rupestre entre afloramentos quartzíticos. Foi coletada com flores e frutos nos meses de julho e agosto.

\section{Verbena L.}

4.1. Verbena rigida Spreng., Syst. veg. ed. 16, 4 (2): 230. 1827. Fig. 2h-k

Subarbustos, monóicos, ca. 0,5 m alt., ramos inermes, decumbentes, tetragonais, híspidoescabros. Folhas 2,5-5 × 0,5-1,6 cm, opostas, lâmina oblongo-elíptica, cartácea, concolor, face adaxial híspida, tricomas apressos, nervuras impressas, face abaxial densamente híspida, tricomas apressos, nervuras proeminentes, tricomas glandulares ausentes, ápice agudo, margem inciso-serrada, ciliada, base subcordada, sésseis. Inflorescências 1-3 cm compr., espigas corimbosas, terminais, trímeras, bracteosas, pedúnculos 6-30 $\mathrm{mm}$ compr., hirsuto, raque hirsuta; brácteas $5 \mathrm{~mm}$ compr., imbricadas, dispostas espiraladamente, estreito-ovais, foliáceas, verdes, externamente pubescente-glandulosas, ápice acuminado, margem ciliada, base truncada; cálice $3 \mathrm{~m}$ compr., 5 laciniado, verde a lilacíneo, externamente pubescente, tubuloso, acrescente no fruto; corola 5-10 mm compr., zigomorfa, hipocrateriforme, tubo cilíndrico, externamente pubescente, 5-lobada, lobos desiguais, emarginados, roxa, fauce roxa, externamente pubescente; estames 4 perfeitos, didínamos, inseridos na metade superior do tubo corola, tecas paralelas; ovário ovoide, 2-locular, lóculos 1-seminado, estigma 2-lobado, um lóbulo obtuso e papiloso, o outro agudo e liso. Fruto esquizocarpo, ca. $0,2 \mathrm{~cm}$ compr., ovoide com ápice alongado, castanho, superfície externa estriada, separando em 4 mericarpos na maturidade.

Material examinado: Lima Duarte, RPPN Serra Negra, 22.II.2008, fl. e fr., F.R.G Salimena et al. 2616 (CESJ); 19.IX.2014, fl. e fr., F.R.G. Salimena et al. 3758 (CESJ).

Verbena ocorre na América tropical e temperada, norte da África, Ásia, Europa e na Austrália. O gênero é representado por cerca de 45 espécies, das quais 16 ocorrem no Brasil (O’Leary et al. 2007; O'Leary 2018).

Verbena rigida pode ser reconhecida pelas folhas oblongo-elípticas, com margem inciso- serreada, ciliada, base subcordada e flores roxas reunidas em espigas corimbosas. Distribui-se pelo Brasil, Paraguai, Bolívia, Uruguai e Argentina (O’Leary et al. 2007). No Brasil ocorre nas regiões Sul e Sudeste, no Cerrado e Floresta Atlântica, em áreas antropizadas, campos de altitude, campos rupestres e floresta ombrófila mista (O'Leary 2018). Está naturalizada no restante da América, em parte da Europa, África do Sul, leste da Ásia e Austrália (O’Leary et al. 2010). Na Serra Negra é encontrada em áreas de campo e borda de mata. Foi coletada com flores e frutos em fevereiro e setembro.

\section{Agradecimentos}

Agradecemos ao Dr. Luiz Menini Neto, a edição das pranchas de ilustração, e à FAPEMIG, a concessão de auxílio ao projeto "Estudos Florísticos na Serra Negra, Minas Gerais" (CRA 1891/06 e CRA 1810-5.02/07).

\section{Referências}

Abreu NL, Menini Neto L \& Konno TUP (2011) Orchidaceae das Serras Negra e do Funil, e similaridade florística entre formações campestres e florestais do Brasil. Acta Botanica Brasilica 25: 58-70.

Atkins S (1995) Verbenaceae. In: Stannard BL (ed.) Flora of the Pico das Almas. Royal Botanic Gardens, Kew. Pp. 621-630.

Atkins S (2004) Verbenaceae. In: Kubtzki K \& Kadereit JW (eds.) The families and genera of vascular plants. Vol. 7. Springer-Verlag, Berlin. Pp. 449-468.

Atkins S (2005) The genus Stachytarpheta (Verbenaceae) in Brazil. Kew Bulletin 60: 161-272.

BFG - The Brazil Flora Group (2015) Growing knowledge: an overview of seed plant diversity in Brazil. Rodriguésia 66: 1085-1113.

Blaser J, Salimena FRG \& Chautems A (2012) Gesneriaceae na Serra Negra, Minas Gerais, Brasil. Rodriguésia 63: 705-714.

Cabral A, Romão GO, Roman SA \& Menini Neto L (2016) Ericaceae da Serra Negra, Minas Gerais, Brasil. Rodriguésia 67: 225-236.

Clarke HD \& Funk VA (2005) Using checklists and collections data to investigate plant diversity: An analysis of five florulas from north eastern South America. Proceedings of the Academy of Natural Sciences of Philadelphia 154: 29-37.

Costa C \& Herrmann G (2006) Plano de ação do Corredor Ecológico da Mantiqueira. Valor Natural, Belo Horizonte. 64p.

Drummond GM, Martins CS, Machado ABM, Sebaio FA \& Antonini Y (2005) Biodiversidade em Minas 
Gerais: Um atlas para sua conservação. $2^{\mathrm{a}}$ ed. Fundação Biodiversitas, Belo Horizonte. 222p.

Dutra SM, Salimena FRG \& Menini Neto L (2012) Annonaceae na Serra Negra, Minas Gerais, Brasil. Rodriguésia 63: 785-793.

Feliciano EA \& Salimena FRG (2011) Solanaceae A. Juss. na Serra Negra, Rio Preto, Minas Gerais. Rodriguésia 62: 55-76.

Fidalgo O \& Bononi VL (1984) Técnicas de coleta, preservação e herborização de material botânico (Manual n. 4). Instituto de Botânica, São Paulo. $62 \mathrm{p}$.

Forzza RC, Menini Neto L, Salimena FRG \& Zappi D (2013) Fanerógamas do Parque Estadual do Ibitipoca e suas relações florísticas com outras áreas com campo rupestre de Minas Gerais. In: Forzza RC, Menini Neto L, Salimena FRG \& Zappi D (orgs.) Flora do Parque Estadual do Ibitipoca e seu entorno. Editora UFJF, Juiz de Fora. Pp. 154-291.

Giulietti AM \& Pirani JR (1988) Patterns of geographic distribuition of some plant species from the Espinhaço Range, Minas Gerais and Bahia, Brazil. In: Vanzolini PE \& Heyer WR (eds.) Proceedings of a workshop on Neotropical distribuition patterns. Academia Brasileira de Ciências, Rio de Janeiro. Pp. 39-69.

Gonçalves EG \& Lorenzi H (2007) Morfologia vegetal: organografia e dicionário ilustrado de morfologia das plantas vasculares. Instituto Plantarum, Nova Odessa. 416p.

Gonzaga DR, Zappi D, Furtado SG \& Menini Neto L (2014) Cactaceae da Serra Negra, Minas Gerais, Brasil. Rodriguésia 65: 443-453.

GSPC (2006) Estratégia global para a conservação de plantas. RBJB/JBRJ/BGCI, Rio de Janeiro. 13p.

Harley RM \& Simmons NA (1986) Florula of Mucugê, Chapada Diamantina, Bahia, Brasil. A descriptive check-list of the campo rupestre area. Royal Botanical Gardens, Kew. 227p.

Harris JG \& Harris MW (2003) Plant identification terminology: an illustrated glossary. $2^{\text {nd }}$ ed. Spring Lake Publ., Spring Lake. 216p.

Hirota MM (2005) Monitoramento da cobertura da Mata Atlântica brasileira. In: Galindo-Leal C \& Câmara IG (eds.) Mata Atlântica: biodiversidade, ameaças e perspectivas. Fundação SOS Mata Atlântica, Belo Horizonte. Pp. 60-65.

Justino LL, Salimena FRG, Campos BC \& Menini Neto L (2016) O clado Merianthera e as tribos Merianieae e Microliceae (Melastomataceae) na Serra Negra, Minas Gerais. Rodriguésia 67: 823-838.

Lorenzi H (1991) Plantas daninhas do Brasil: terrestres, aquáticas, parasitas, tóxicas e medicinais. $2^{\mathrm{a}}$ ed. Plantarum, Nova Odessa. 440p.

Lorenzi H \& Souza HS (2001) Plantas ornamentais do Brasil: arbustivas, herbáceas e trepadeiras. Instituto
Plantarum de Estudos da Flora, Nova Odessa. Pp. 1030-1056

Luizi-Ponzo AP (1997) Verbenaceae. In: Marques MCM, Vaz ASF \& Marquete R (eds.) Flórula da APA Cairuçu, Parati, Rio de Janeiro. Instituto de Pesquisas Jardim Botânico do Rio de Janeiro. Série Estudos e Contribuições 14: 558-564.

Matozinhos CN \& Konno TUP (2011) Diversidade taxonômica de Apocynaceae na Serra Negra, MG, Brasil. Hoehnea 38: 569-595.

Menini Neto L, Matozinhos CN, Abreu NL, Valente ASM, Antunes K, Souza FS, Viana PL \& Salimena FRG (2009) Flora não-arbórea de uma floresta de grota na Serra da Mantiqueira, Zona da Mata de Minas Gerais, Brasil. Biota Neotropica 9: 1-13.

Mezzonato-Pires AC, Salimena FRG \& Bernacci LC (2013) Passifloraceae Juss. ex Russel na Serra Negra, Minas Gerais, Brasil. Rodriguésia 64: 123-136.

Moro MF, Souza VC, Oliveira-Filho AT, Queiroz LP, Fraga CN, Rodal MJN, Araújo FS \& Martins FR (2012) Alienígenas na sala: o que fazer com espécies exóticas em trabalhos de taxonomia, florística e fitossociologia? Acta Botanica Brasilica 26: 991-999.

O'Leary N (2018) Verbena in Flora do Brasil 2020 em construção. Instituto de Pesquisas Jardim Botânico do Rio de Janeiro. Disponível em $<$ http:// floradobrasil.jbrj.gov.br/reflora/floradobrasil/ FB15214>. Acesso em 27 março 2018.

O’Leary N, Múlgura ME \& Morrone O (2007) Revisión taxonómica de las especies del género Verbena L. (Verbenaceae): serie Pachystachyae. Annals Missouri Botanical Garden 94: 571-622.

O’Leary N, Múlgura ME \& Morrone O (2010) Revisión taxonómica de las especies del género Verbena L. (Verbenaceae) II: serie Verbena. Annals Missouri Botanical Garden 97: 369-428.

O’Leary N, Denham SS, Salimena FRG \& Múlgura ME (2012) Species delimitation in Lippia section Goniostachyum (Verbenaceae) using the phylogenetic species concept Botanical Journal of the Linnean Society 170: 197-219.

Pascual ME, Slowing K, Carretero E, Mata DM \& Villar A (2001) Lippia: traditional uses, chemistry and pharmacology: a review. Journal of Ethonopharmacology 6: 201-214.

Radford AE (1974) Fundamental of plant systematics. Harper \& Row, New York. 507p.

Salimena-Pires FR \& Giulietti AM (1998) Flora da Serra do Cipó, Minas Gerais: Verbenaceae. Boletim de Botânica da Universidade de São Paulo 17: 155-186.

Salimena FRG (2000) Verbenaceae. In: Melo MMRF, Barros F, Wanderley MGL, Kirizawa M, JungMendaçolli SL \& Chiea SAC (eds.) Flora fanerogâmica da Ilha do Cardoso, São Paulo. Vol. 7. Instituto de Botânica, São Paulo. Pp. 7-26. 
Salimena FRG, França F \& Silva TRS (2009) Verbenaceae. In: Giulietti AM, Rapini A, Andrade MJG, Queiroz LP \& Silva JMC (orgs.) Plantas raras do Brasil. Conservação Internacional, Belo Horizonte. Pp. 399-405.

Salimena FRG \& Silva TRS (2009) Flora de Grão-Mogol, Minas Gerais: Verbenaceae. Boletim de Botânica da Universidade de São Paulo 27: 119-126.

Salimena FRG, Kutschenko DC, Monteiro NP \& Mynssen C (2013) Verbenaceae. In: Martinelli G \& Moraes MA (orgs.) Livro vermelho da flora do Brasil. CNCFlora, Rio de Janeiro. Pp. 1010-1016.

Salimena FRG, Matozinhos CN, Abreu NL, Ribeiro JHC, Souza FS \& Menini Neto L (2013) Flora fanerogâmica da Serra Negra, Minas Gerais, Brasil. Rodriguésia 64: 311-320.

Salimena FRG, Moraes L, Kutschenko DC \& Novaes L (2014) Verbenaceae. In: Martinelli G, Messina T \& Santos-Filho L (orgs.) Livro vermelho da flora do Brasil - Plantas raras do Cerrado. CNCFlora, Rio de Janeiro. Pp. 266-273.

Salimena FRG, Ferreira SC, Cardoso PH \& Valério VIR (2016) Verbenaceae. In: Rizzo JA (ed.) Flora dos estados de Goiás e Tocantins. Coleção Rizzo. Vol. 47. Universidade Federal de Goiás, Goiânia. Pp. 1-157.

Santos JS, Melo JIM, Abreu MC \& Sales MF (2009)
Verbenaceae sensu stricto na região de Xingó: Alagoas e Sergipe, Brasil. Rodriguésia 60: 985-998.

Schauer JC (1847) Verbenaceae. In: de Candolle, AP (ed.) Prodromus systematis naturalis regni vegetabilis. Victor Masson, Paris. Vol. 11. Pp. 522-700.

Silva TRS (1999) Redelimitação e revisão taxonômica do gênero Lantana L. (Verbenaceae) no Brasil. Tese de Doutorado. Universidade de São Paulo, São Paulo. 174p.

Silva TRS \& Lima CT (2012) Flora of Bahia: Verbenaceae: Lantana. Sitientibus série Ciências Biológicas 12: 245-268.

Stashenko EE, Jaramillo BE \& Martínez JR (2003) Comparación de la composición química y de la actividad antioxidante in vitro de los metabolitos secundarios volátiles de plantas de la familia Verbenaceae. Revista de La Academia Colombiana de Ciencias Exactas, Físicas y Naturales 27: 579-598.

Thiers B [continuamente atualizado]. Index herbariorum: a global directory of public herbaria and associated staff.New York BotanicalGarden's Virtual Herbarium. Disponível em $<$ http://sweetgum.nybg. org/ih/>. Acesso em 30 novembro 2016.

Valente ASM, Garcia PO, Salimena FRG \& Oliveira-Filho AT (2011) Composição, estrutura e similaridade florística da Floresta Atlântica, na Serra Negra, Rio Preto - MG. Rodriguésia 62: 321-340. 